\title{
Influence of Annealing on Properties of Spray Deposited ZnO Thin Films
}

\author{
Kalyani Nadarajah, Ching Yern Chee, and Chou Yong Tan \\ Department of Mechanical Engineering, Faculty of Engineering, University of Malaya, Lembah Pantai, \\ 50603 Kuala Lumpur, Malaysia
}

Correspondence should be addressed to Ching Yern Chee; chingyc@um.edu.my

Received 8 August 2013; Revised 18 October 2013; Accepted 21 October 2013

Academic Editor: Mengnan Qu

Copyright (c) 2013 Kalyani Nadarajah et al. This is an open access article distributed under the Creative Commons Attribution License, which permits unrestricted use, distribution, and reproduction in any medium, provided the original work is properly cited.

\begin{abstract}
Zinc Oxide $(\mathrm{ZnO})$ thin films were deposited on glass substrates via the spray pyrolysis technique. The films were subsequently annealed in ambient air from $300^{\circ} \mathrm{C}$ to $500^{\circ} \mathrm{C}$. The morphology and structural properties of the thin films were studied by field emission scanning electron microscope (FESEM), atomic force microscopy (AFM), and X-ray diffractometry (XRD) techniques. Electrical resistivity of the thin films was measured using a data acquisition unit. The optical properties of the films were characterized by UV-vis spectroscopy and photoluminescence (PL) technique. X-ray diffraction data showed that the films were grown in the (002) direction with a hexagonal wurtzite structure. The average grain size ranged from 15 to $27 \mathrm{~nm}$. Increasing annealing temperatures resulted in larger grain sizes and higher crystallinity, with the surface roughness of annealed films being more than twice if compared to unannealed film. The electrical resistivity of the films decreased with the increasing annealing temperature. The UV and visible band emissions were observed in the photoluminescence spectra, due to exciton and defect-related emissions, respectively. The transmission values of the films were as high as $90 \%$ within the visible range $(400-700 \mathrm{~nm})$.
\end{abstract}

\section{Introduction}

Currently, $\mathrm{ZnO}$ nanomaterials are being applied in electronics, photonics, catalysis, lighting, and chemical sensing. It is well known that $\mathrm{ZnO}$ exhibits many favorable properties, such as high chemical stability, wide bandgap of $3.37 \mathrm{eV}$, high exciton binding energy of $60 \mathrm{meV}$, and abundance in nature, and is also regarded as nontoxic $[1,2]$. Highquality $\mathrm{ZnO}$ films are mainly fabricated by using physical and chemical methods. The physical methods include sputtering [3], molecular beam epitaxy [4], and laser ablation [5], while the chemical method includes spray pyrolysis [6], chemical vapor deposition (CVD) [7], sol-gel [8], spin coating [9], dip coating [10], and electrodeposition [11]. Most of the methods mentioned in the literature are not ideally suited for large area coatings. However, the spray pyrolysis method is one of the best methods to produce large area coatings based on the previous studies [3-11]. Additionally, it is simple, has low temperature deposition, is cost-effective, has good adhesion between films and substrate, and demonstrates uniform particle distribution, high purity, and excellent optical properties [12]. Some of the main factors affecting the properties of the film that uses spray pyrolysis technique are chemical solution (chemical composition, concentration), the distance between the substrate and atomizer interaction during film deposition, spray temperatures, substrate homogeneity, annealing conditions, and spray rates [13]. The spray pyrolysis method is efficient in producing thin film, multilayer film, thick film, and porous film on an inexpensive substrate [12]. Several oxides, such as $\mathrm{ZnO}$ [14], $\mathrm{CdO}$ [15], $\mathrm{TiO}_{2}$ [16], $\mathrm{SnO}_{2}$ [17], $\mathrm{NiO}$ [18], and $\mathrm{Bi}_{2} \mathrm{O}_{3}$ [19], have been deposited using a spray pyrolysis method. This technique involves a water/alcohol solution of metal salts sprayed onto a heated substrate, followed by allowing it to decompose into an oxide film. The formation of oxide due to the decomposition reaction is thermodynamically feasible and leaves no residue on other reactants. The substrate temperature strongly affects film morphology. By increasing the temperature, the film's morphology can be changed from a cracked to a porous structure [20]. The types and 


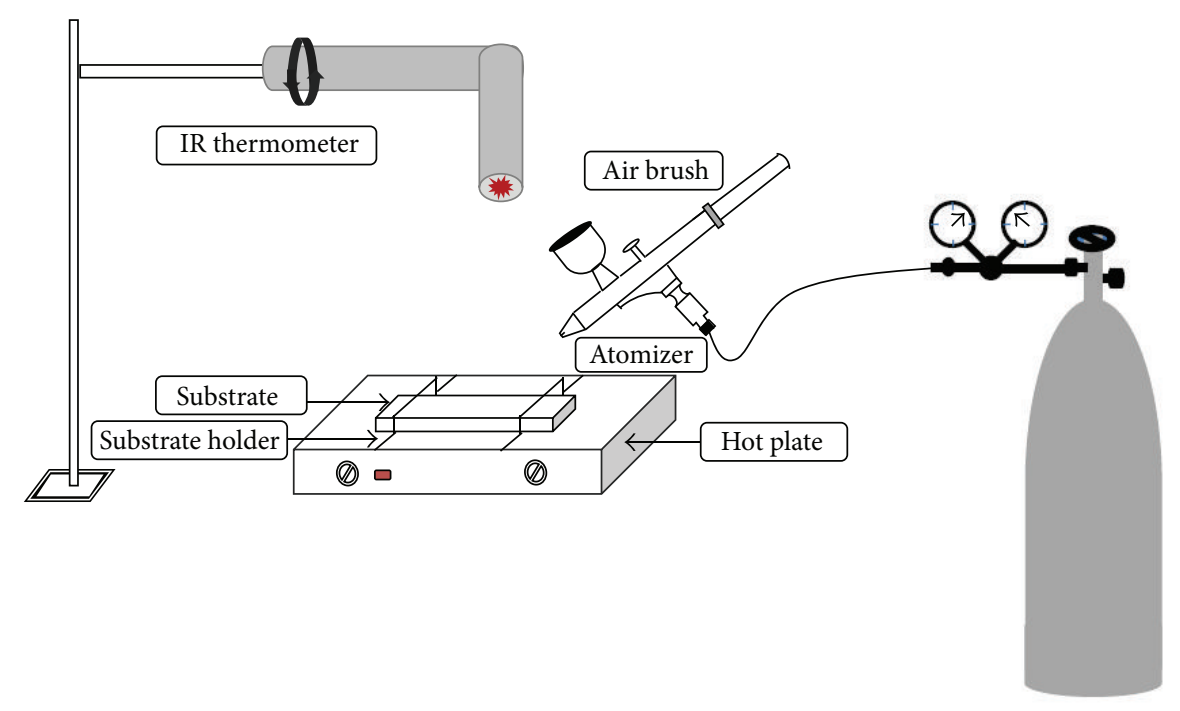

FIGURE 1: Schematic diagram of spray pyrolysis experimental setup.

concentrations of precursor and additive elements are other vital variables that influence the properties and structure [21]. The unannealed spray deposited film has high resistivity, low roughness, and less transparency due to its low crystallinity and the presence of organic residues [22-24]. The properties of the unannealed film can be enhanced due to the thermal annealing, plasma treatment, and laser treatment $[25,26]$. Of these options, the thermal annealing is one of the simplest and effective ways to treat the spray deposited films. The thermal annealing temperatures, time, and various gaseous environments influence films and structural defects in the materials. During the thermal annealing process, dislocations and other structural defects in the material, adsorption, or decomposition are retained on the surface; therefore, the structure and the stoichiometric ratio of the material are altered [27]. Oxygen interstitials, zinc interstitials, oxygen vacancies, zinc vacancies, and excess oxygen are common defects found in deposited $\mathrm{ZnO}$ films. Zinc interstitial and oxygen vacancies are the most common defects $[28,29]$.

Nunes et al. [30, 31] reported the deposition of $\mathrm{ZnO}$ thin films using zinc acetate as a precursor. Their work reported the structural, optical, and electrical properties of undoped and doped $\mathrm{ZnO}$ thin films under different conditions. Yoon and Cho [32] demonstrated the synthesis of $\mathrm{ZnO}$ thin films using a zinc acetate dihydrate as a precursor. Their work reported on the effects of different substrate temperatures and heat treatments on the luminescence properties of $\mathrm{ZnO}$ film. Ayouchi et al. [33] also synthesized $\mathrm{ZnO}$ thin films using zinc acetate precursor and described the effects of substrate temperature and the physical properties of $\mathrm{ZnO}$ thin films. Despite our knowledge of various influences on film structure, the effects of annealing temperature on the $\mathrm{ZnO}$ films prepared by spray pyrolysis are unknown. In this study, the effects of annealing on the structural, morphological, electrical, optical, and photoluminescence behavior of $\mathrm{ZnO}$ films are investigated.

\section{Experimental}

2.1. Sample Preparation. The $\mathrm{ZnO}$ thin films were deposited on glass and Si substrates using spray pyrolysis techniques. The substrates were ultrasonically cleaned in methanol and acetone for 20 minutes and then immersed into $0.1 \mathrm{M} \mathrm{HCl}$ for 12 hours to remove the ionic contamination and metal residues. These substrates were rinsed with deionized water and dried in ambient air prior to the deposition. 0.1 $\mathrm{M}$ zinc acetate $\left(\mathrm{Zn}\left(\mathrm{C}_{2} \mathrm{H}_{3} \mathrm{O}_{2}\right)_{2} 99.9 \%\right.$ purity Sigma Aldrich) was used as a precursor. $\mathrm{A} 2 \mathrm{~mL}$ acetic acid was added to the ethanol to assist in the complete dissolution of the zinc acetate. A schematic diagram of the spray pyrolysis system is illustrated in Figure 1. The precursor solution was atomized into fine uniform droplets on the heated substrate using the spray gun which is connected with nitrogen gas. The substrate was heated to $250^{\circ} \mathrm{C}$ during the deposition process. The outlet gas pressure was kept constant at $30 \mathrm{psi}$. The distance between the substrate and target was kept at $100 \mathrm{~mm}$, and spray rate was $30 \mathrm{sec}$. After spraying, the deposited films were annealed in ambient air from $300^{\circ} \mathrm{C}$ to $500^{\circ} \mathrm{C}$ for 120 minutes. The annealing temperature was conducted until $500^{\circ} \mathrm{C}$ in this study since further increase of the temperature would cause the bending of the soda-lime glass substrate.

2.2. Characterization of Film. The morphologies of the film and grain size were studied with a Zeiss Ultra-60 field emission scanning electron microscopy (FESEM). The roughness and surface morphology were evaluated using an Ambios 4500 model atomic force microscope (AFM). Film crystallinity was characterized by Bruker X-ray diffraction (XRD) with $\mathrm{CuK} \alpha$ radiation. The electrical resistivity of the film was measured using data acquisition unit. The film thickness was measured using KLA Tencor surface profile. The crystalline quality of the film was studied using Renishaw inVia Raman spectroscope with a He-Cd laser at $325 \mathrm{~nm}$. 


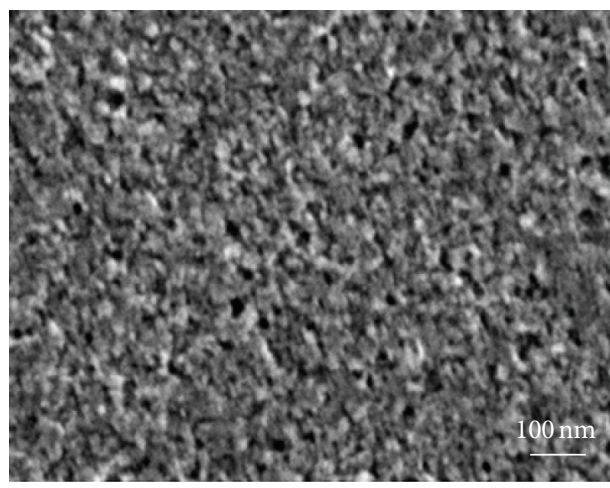

(a)

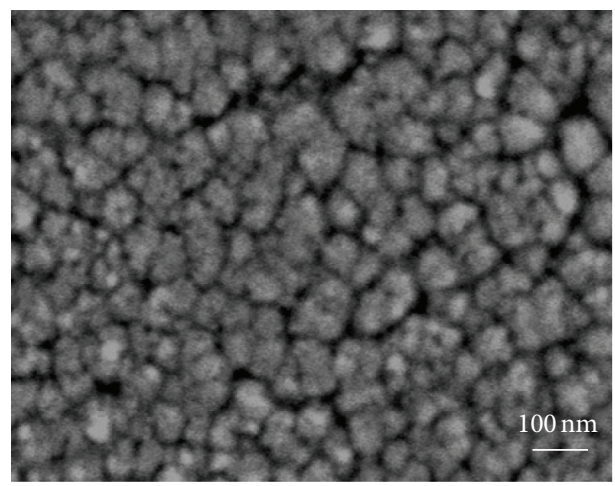

(c)

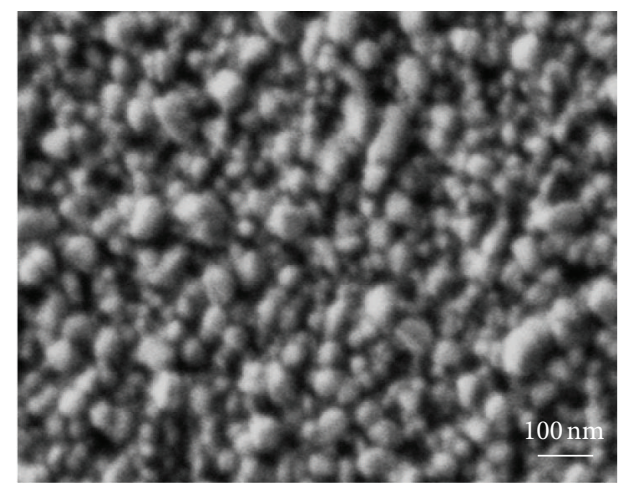

(b)

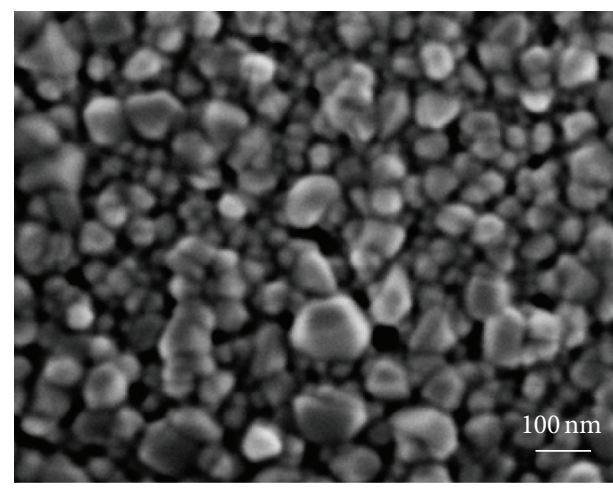

(d)

FIGURE 2: FESEM images of $\mathrm{ZnO}$ thin film deposited on Si substrate (a) unannealed, (b) annealed at $300^{\circ} \mathrm{C}$, (c) annealed at $400^{\circ} \mathrm{C}$, and (d) annealed at $500^{\circ} \mathrm{C}$.

Optical transmission spectra were characterized using a double beam UV-vis spectrophotometer (Cary 50) in the wavelength range of $300-800 \mathrm{~nm}$.

\section{Results and Discussion}

3.1. Surface Morphology Study of Films by FESEM. Figure 2 illustrates the surface morphologies of the films before and after annealing $\left(300^{\circ} \mathrm{C}\right.$ and $\left.500^{\circ} \mathrm{C}\right)$ process. It appears that the grain size and morphology of the films improved with the increasing annealing temperatures. The FESEM micrograph shows that the unannealed films are not compact and have very small crystallites on $\mathrm{Si}$ substrate, which occur due to incomplete intermediate products from the spray pyrolysis technique. The well-defined round shapes of the grains are observed in the film at an annealing temperature of $300^{\circ} \mathrm{C}$. A $30 \mathrm{~nm}$ average grain size of $\mathrm{ZnO}$ films is achieved when the annealing temperature reaches $500^{\circ} \mathrm{C}$. The grain size increases with the increase in the annealing temperatures, due to reduction of grain boundaries in $\mathrm{ZnO}$ thin film [34].

3.2. AFM Morphology Study of Films. Figures 3(a) to 3(c) show the AFM images with the corresponding rms value of unannealed and annealed $\mathrm{ZnO}$ thin films grown on $\mathrm{Si}$ substrates. For the unannealed films (Figure 3(a)), the result exhibits less elongated grains over the surface. Figures 3(b) and 3(c) display fine grains that exhibit greatly improved vertical alignment (nanotips-like morphology) than the unannealed films, which is consistent with the FESEM results. The surface roughness of the $\mathrm{ZnO}$ film is determined using AFM software. The rms roughness value can be estimated using the following formula [35]:

$$
R(\mathrm{rms})=\left(\frac{\sum_{I=1}^{N}\left(Z_{i}-Z_{\mathrm{avg}}\right)^{2}}{N}\right)^{1 / 2},
$$

where $N$ is the number of points, $Z_{i}$ is the $i$ th point of $Z$, and $Z_{\text {avg }}$ is the average value of the $Z$. The unannealed film roughness is $2.1 \mathrm{~nm}$. After being annealed at $300^{\circ} \mathrm{C}$, $400^{\circ} \mathrm{C}$, and $500^{\circ} \mathrm{C}$, the film's roughness increased to $4.3 \mathrm{~nm}$, $5.4 \mathrm{~nm}$, and $5.6 \mathrm{~nm}$, respectively. The measurements of samples revealed that the average roughness of annealed films increased compared to that of the unannealed film. As a result of this, the annealing temperature enhances elongated grains over the surface of the film, which leads to the slight increase of surface roughness. Tong et al. [36] have reported that an increase of roughness is suitable for the growth of $\mathrm{ZnO}$ nanowires on $\mathrm{ZnO}$ thin films.

3.3. Structural Studies of Films. The phase composition of $\mathrm{ZnO}$ thin films is determined using XRD at room temperature, with monochromatic $\mathrm{CuK} \alpha(\lambda=0.15406 \mathrm{~nm})$. The 


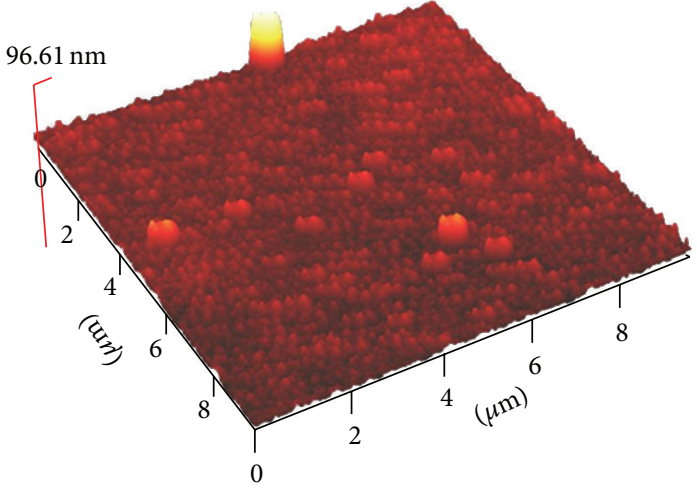

(a)

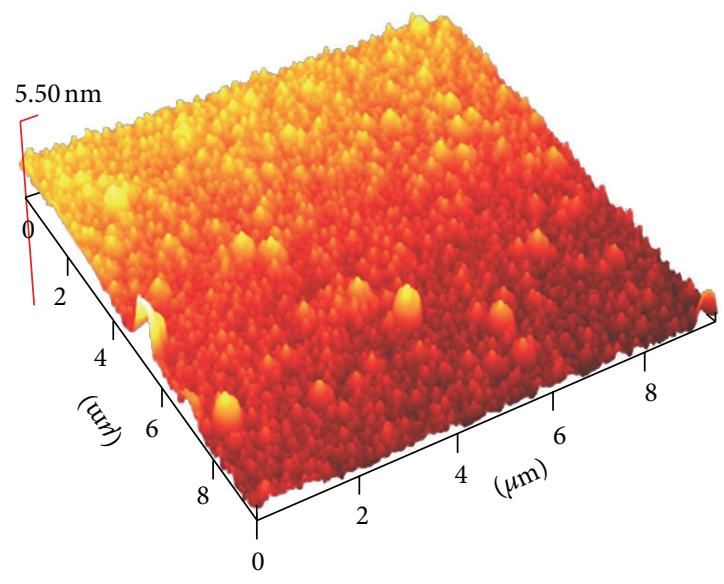

(c)
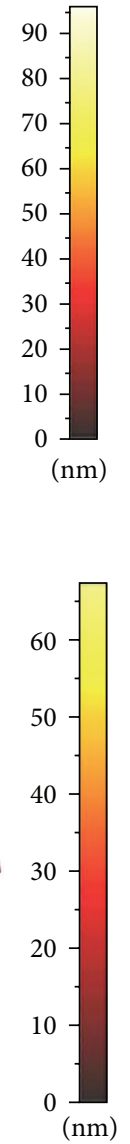

$(\mathrm{nm})$

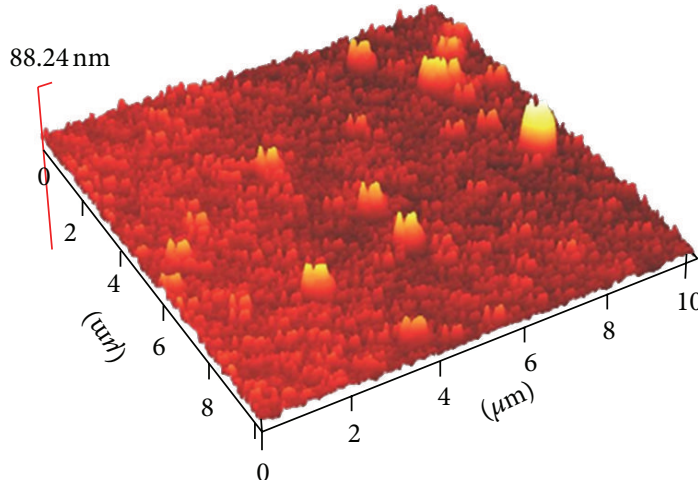

(b)

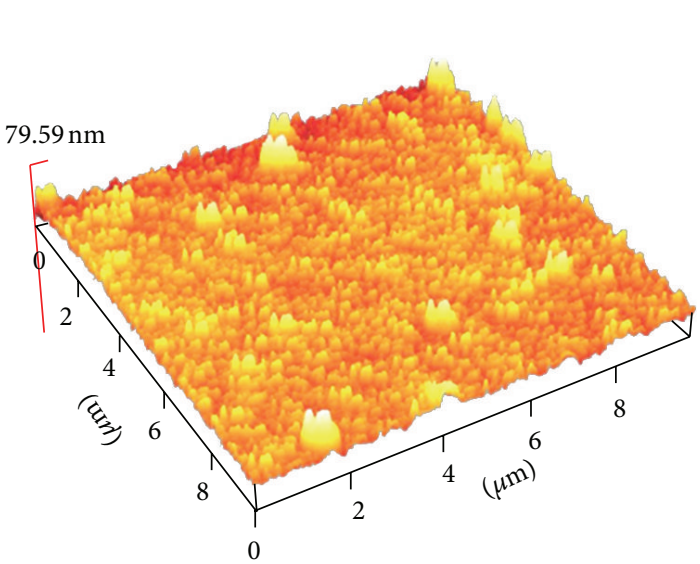

(d)
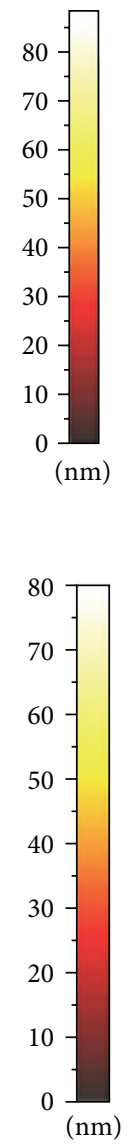

$(\mathrm{nm})$

FIGURE 3: AFM images of $\mathrm{ZnO}$ thin film deposited on Si substrate (a) unannealed, (b) annealed at $300^{\circ} \mathrm{C}$, (c) annealed at $400^{\circ} \mathrm{C}$, and (d) annealed at $500^{\circ} \mathrm{C}$.

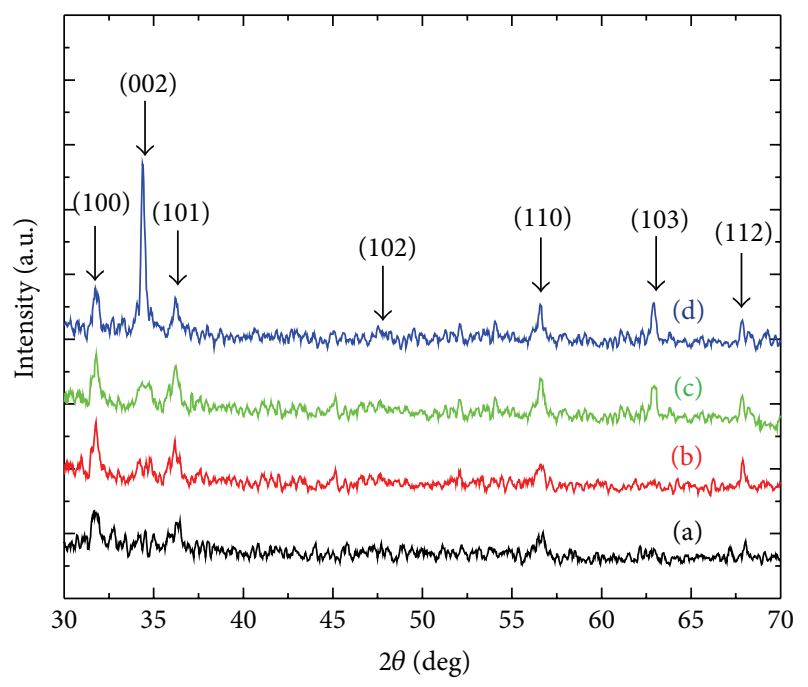

Figure 4: XRD pattern of $\mathrm{ZnO}$ thin film on Si substrate (a) unannealed, (b) annealed at $300^{\circ} \mathrm{C}$, (c) annealed at $400^{\circ} \mathrm{C}$, and (d) annealed at $500^{\circ} \mathrm{C}$. intensity data is collected over a range of $2 \theta$, from $30^{\circ}$ to $70^{\circ}$, with a scan rate of $0.03 \mathrm{deg} / \mathrm{s}$. The XRD spectra of the spray pyrolysis deposited unannealed and annealed $\mathrm{ZnO}$ films on $\mathrm{Si}$ substrate are illustrated in Figure 4 . $\mathrm{ZnO}$ diffraction peaks are indexed as (100), (101), (002), (102), (110), (103), and (112) for corresponding peak positions of $31.766^{\circ}, 34.419^{\circ}, 36.251^{\circ}$, $47.536^{\circ}, 56.591^{\circ}, 62.852^{\circ}$, and $67.942^{\circ}$. These diffraction peaks' position and intensities quantities are well matched with the Joint Committee on Powder Diffraction Standards (JCPDS) card no. 067454. The patterns observed from the XRD measurements show that the films possess the hexagonal wurtzite structure and a space group $\mathrm{P}_{3} \mathrm{mc}$. The unannealed film shows lower diffraction peak intensities compared to that of the annealed film. The diffraction peaks intensities increase with the increasing annealing temperatures. Thus, the $500^{\circ} \mathrm{C}$ annealed film shows a strong preferential growth orientation along the (002) plane. The diffraction peaks of the film become more intense when the annealing temperature increases, which in turn leads to increase in the grain size, as well as the enhancement of crystallinity. The full width half maxima (FWHM) values decrease with increasing annealing 


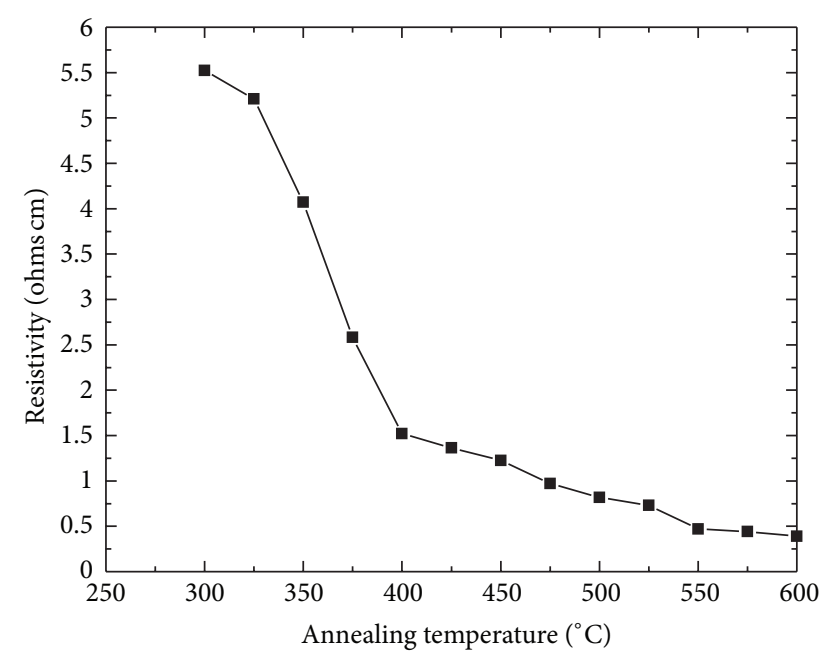

FIGURE 5: Electrical resistivity variation of $\mathrm{ZnO}$ thin film on glass substrate as a function of annealing temperatures.

temperatures. The grain size $(D)$ can be computed using the following Scherrer's formula [37]:

$$
D=\frac{0.94 \lambda}{\beta \cos \theta},
$$

where $\beta$ is FWHM, $\lambda$ is wavelength of $\mathrm{X}$-ray, and $\theta$ is Bragg's diffraction angle. Furthermore, the average grain sizes are estimated to be around $15,20,22$, and $27 \mathrm{~nm}$ for unannealed and $300^{\circ} \mathrm{C}, 400^{\circ} \mathrm{C}$, and $500^{\circ} \mathrm{C}$ annealed films, respectively. The decrease of FWHM with the increase of annealing temperature can be attributed to the increase of grain sizes. This correlates with the findings reported by previous researchers $[24,38]$.

3.4. Electrical Resistivity Study of Films. Figure 5 illustrates the electrical resistivity of $\mathrm{ZnO}$ thin films as a function of annealing temperatures. The electrical resistivity is greatly influenced by the annealing temperatures. It is observed that the resistivity of the film decreases dramatically up to $400^{\circ} \mathrm{C}$ and again decreases slowly afterward. This might be due to either an increase in the mobility and/or increase of the carriers. The increase of annealing temperature is attributed to larger grain sizes, thus leading to the increase of mobility change that has been reported in the literature [39]. At room temperature, there are very small numbers of charge carriers that are available in $\mathrm{ZnO}$. The electronically active carriers increase when the temperature increases, thereby leading to an excess carrier in the conduction band. This increase in carriers occurs due to thermal excitation giving rise to the conductivity of the films. Similar results have been reported in the literature [40]. The resistivity of the $500^{\circ} \mathrm{C}$ annealed film is measured to be $0.81 \Omega \mathrm{cm}$.

3.5. Photoluminescence Studies of Films. The room temperature photoluminescence (PL) spectra of unannealed and annealed $\mathrm{ZnO}$ thin films on glass substrate are illustrated in Figure 6 . There are three peaks positions that are observed

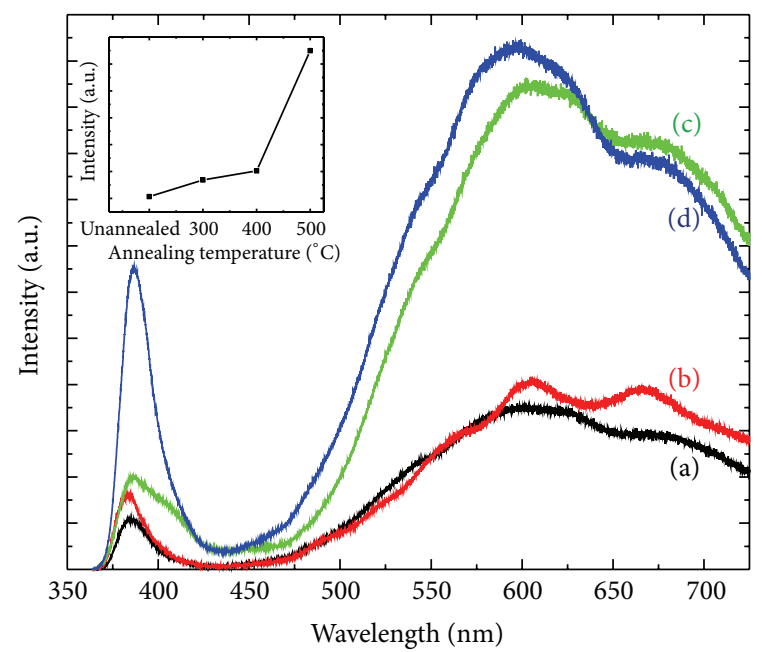

FIGURE 6: The photoluminescence spectra of $\mathrm{ZnO}$ thin film on glass substrate (a) unannealed, (b) annealed at $300^{\circ} \mathrm{C}$, (c) annealed at $400^{\circ} \mathrm{C}$, and (d) annealed at $500^{\circ} \mathrm{C}$. The inset shows the intensity variation of near band edge emission at different annealed temperatures.

from the spectra. For unannealed films, the PL spectrum consists of three emission bands: a strong UV emission band at $\sim 382 \mathrm{~nm}(3.25 \mathrm{eV})$, yellow band at $\sim 603 \mathrm{~nm}(2.06 \mathrm{eV})$, and orange-red band at $\sim 672 \mathrm{~nm}(1.85 \mathrm{eV})$, respectively. The band emission occurring in the UV range is due to excitonic recombination, while the band emission existing at the visible emission band is due to the recombination of deep-level holes and electrons [41]. All of the deep-level emissions are correlated to the defects arising during the growth of crystallites and are related to the change of crystallinity due to zinc interstitials, zinc vacancies, oxygen interstitials, oxygen vacancies, and dislocations [42]. Previous works [43, 44] reported that the yellow-orange emission originated from oxygen interstitials in $\mathrm{ZnO}$, while the orange-red emission could be related to excess oxygen on the $\mathrm{ZnO}$ surface. From the spectra, it is observed that the PL peak intensity increases with the increasing annealing temperature. The increase of the visible emissions of the $\mathrm{ZnO}$ film is due to the increase of the oxygen interstitials and excess oxygen concentrations [45] by the increase of annealing temperature. The UV peak position is red shifted from $3.25 \mathrm{eV}$ (for unannealed film) to $3.22 \mathrm{eV}$ (for $500^{\circ} \mathrm{C}$ annealed film). The red shift can be explained by the quantum confinement theory, which states that the energy bandgap of a semiconductor decreases with increasing grain sizes [46]. However, after annealing, the yellow emission is improved with a blue shift towards a wavelength of $594 \mathrm{~nm}$. Fujihara et al. [47] and Chen et al. [48] have also reported a blue shift in their studies.

The inset of Figure 6 shows the UV portion of the PL emission centered at $385 \mathrm{~nm}$ as a function of annealing temperatures. The intensity of UV-PL peak increases with the increasing annealing temperature, as shown in the inset of Figure 6. The increase in the UV portion of the PL emission is due to the removal of microstructural defects and homogenization of the films. 


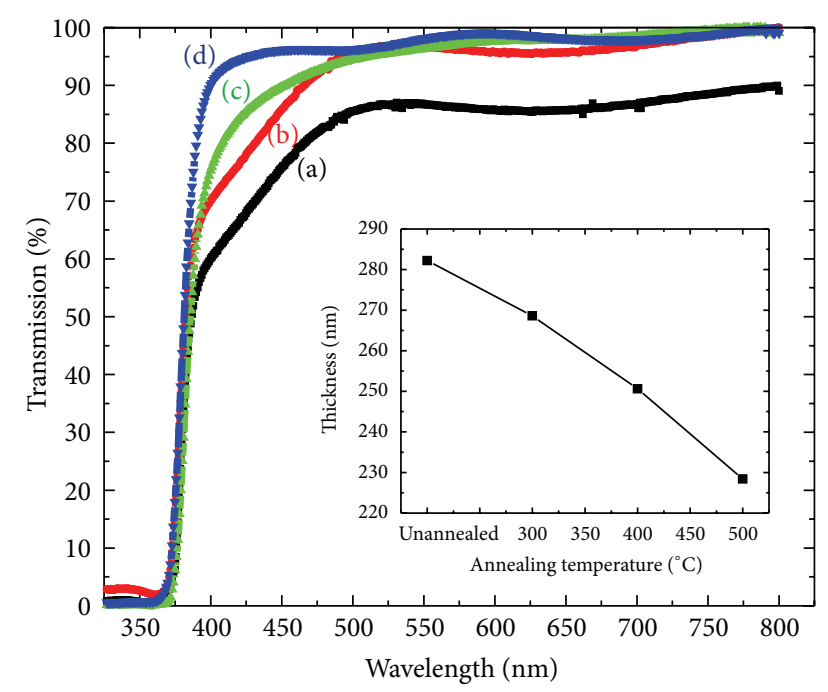

Figure 7: The transmission spectra of $\mathrm{ZnO}$ thin film on glass substrate (a) unannealed, (b) annealed at $300^{\circ} \mathrm{C}$, (c) annealed at $400^{\circ} \mathrm{C}$, and (d) annealed at $500^{\circ} \mathrm{C}$. The inset shows the films thickness variation of different annealed temperatures.

3.6. Transmission Studies of $\mathrm{ZnO}$ Thin Films. The optical transmission of $\mathrm{ZnO}$ films is carried out using a double beam spectrophotometer in the wavelength range from 300 to $800 \mathrm{~nm}$. Figure 7 shows optical transmission spectra of both unannealed and annealed $\mathrm{ZnO}$ thin films. The average transmittance values are directly related to the thickness of films. The inset in Figure 7 illustrates the average thickness variation of the films with the increase of annealing temperatures. The thickness of unannealed film is $282.2 \mathrm{~nm}$. After annealing at $300^{\circ} \mathrm{C}, 400^{\circ} \mathrm{C}$, and $500^{\circ} \mathrm{C}$, the film thickness decreases to $268.6 \mathrm{~nm}, 250.6 \mathrm{~nm}$, and $228.4 \mathrm{~nm}$, respectively. The relationship between the optical transmission and thickness is given by the Beer-Lambert equation as follows [49]:

$$
T=\frac{I}{I_{o}}=e^{(-\alpha t)}
$$

where $I$ is the transmitted intensity at a particular wavelength, $I_{o}$ is the incident light intensity, $\alpha$ is the absorption coefficient, and $t$ is the film thickness. The equation shows that the optical transmission of the $\mathrm{ZnO}$ films will decrease inversely proportional to the film thickness. The optical transmission is inversely proportional to the thickness of the films. The transmission in the visible region of the unannealed film is approximately $80 \%$. The visible transmission of the $\mathrm{ZnO}$ films increases from $90 \%$ to $92 \%$ when annealing temperature increased from $300^{\circ} \mathrm{C}$ to $400^{\circ} \mathrm{C}$. The transmission film approaches to $96 \%$ when the annealing temperature reached $500^{\circ} \mathrm{C}$. A very steep absorption edge near $370 \mathrm{~nm}$ is observed for both unannealed and annealed films indicating high crystal quality, which could enhance luminescent efficiency. The transmission of films increases in tandem with annealing temperatures due to the increase in grain sizes, structural homogeneity, and crystallinity. The same observation has been reported by previous researchers [50, 51]. Jayatissa et al. [52] have demonstrated that the transmission of $\mathrm{ZnO}$ films can be improved by annealing, which could lead to the reaction of oxygen with $\mathrm{ZnO}$. It suggests that ambient conditions annealing would greatly influence the optical transmission of $\mathrm{ZnO}$ films. This is especially valuable for the applications as a front electrode and window materials in solar cell.

\section{Conclusions}

$\mathrm{ZnO}$ thin films were prepared by spray pyrolysis method, and it was thermally annealed at different temperatures. The structural, electrical, and optical properties of the $\mathrm{ZnO}$ thin films were characterized using XRD, AFM, data acquisition unit, and UV-vis spectrophotometer. The grain size of the films increases with the increase of annealing temperatures. The XRD diffractogram revealed that the thermal annealed film at $500^{\circ} \mathrm{C}$ possesses good crystalline hexagonal wurtzite structure, with a preferred plane orientation along (002). The grain size estimated from FESEM analysis is in good agreement with XRD data. The PL emission of the samples shows a narrow emission centered at $385 \mathrm{~nm}$ and a broad peak emission located at $594 \mathrm{~nm}$ and $672 \mathrm{~nm}$. The $\mathrm{ZnO}$ films show an increase of transmission with the increase of annealing temperature. In particular, $\mathrm{ZnO}$ film annealed at $500^{\circ} \mathrm{C}$ achieves high light transmission of $96 \%$ in the visible range with low electrical resistivity of $0.82 \Omega \mathrm{cm}$. These properties render that the $\mathrm{ZnO}$ film is attractive to optoelectronic device applications.

\section{Acknowledgment}

The authors acknowledge financial support from the University Malaya Postgraduate Research Grant of nos. PV0332012A, CG013-2013, CG07-2013, RP011A-13AET, FP0302013A, and ER014-2012A.

\section{References}

[1] J.-H. Lee, K.-H. Ko, and B.-O. Park, "Electrical and optical properties of $\mathrm{ZnO}$ transparent conducting films by the sol-gel method," Journal of Crystal Growth, vol. 247, no. 1-2, pp. 119-125, 2003.

[2] R. Könenkamp, K. Boedecker, M. C. Lux-Steiner et al., "Thin film semiconductor deposition on free-standing $\mathrm{ZnO}$ columns," Applied Physics Letters, vol. 77, no. 16, pp. 2575-2577, 2000.

[3] S. Eisermann, J. Sann, A. Polity, and B. K. Meyer, "Sputter deposition of $\mathrm{ZnO}$ thin films at high substrate temperatures," Thin Solid Films, vol. 517, no. 20, pp. 5805-5807, 2009.

[4] D. C. Look, D. C. Reynolds, C. W. Litton, R. L. Jones, D. B. Eason, and G. Cantwell, "Characterization of homoepitaxial ptype $\mathrm{ZnO}$ grown by molecular beam epitaxy," Applied Physics Letters, vol. 81, no. 10, pp. 1830-1832, 2002.

[5] M. Hiramatsu, K. Imaeda, N. Horio, and M. Nawata, “Transparent conducting $\mathrm{ZnO}$ thin films prepared by $\mathrm{XeCl}$ excimer laser ablation," Journal of Vacuum Science and Technology A, vol. 16, no. 2, pp. 669-673, 1998.

[6] R. Ayouchi, D. Leinen, F. Martín, M. Gabas, E. Dalchiele, and J. R. Ramos-Barrado, "Preparation and characterization of transparent $\mathrm{ZnO}$ thin films obtained by spray pyrolysis," Thin Solid Films, vol. 426, no. 1-2, pp. 68-77, 2003. 
[7] S. Faÿ, U. Kroll, C. Bucher, E. Vallat-Sauvain, and A. Shah, "Low pressure chemical vapour deposition of $\mathrm{ZnO}$ layers for thinfilm solar cells: temperature-induced morphological changes," Solar Energy Materials and Solar Cells, vol. 86, no. 3, pp. 385397, 2005.

[8] D. Bao, H. Gu, and A. Kuang, "Sol-gel-derived c-axis oriented ZnO thin films," Thin Solid Films, vol. 312, no. 1-2, pp. 37-39, 1998.

[9] G. Srinivasan, N. Gopalakrishnan, Y. S. Yu, R. Kesavamoorthy, and J. Kumar, "Influence of post-deposition annealing on the structural and optical properties of $\mathrm{ZnO}$ thin films prepared by sol-gel and spin-coating method," Superlattices and Microstructures, vol. 43, no. 2, pp. 112-119, 2008.

[10] C. J. Brinker, G. C. Frye, A. J. Hurd, and C. S. Ashley, "Fundamentals of sol-gel dip coating," Thin Solid Films, vol. 201, no. 1, pp. 97-108, 1991.

[11] E. A. Dalchiele, P. Giorgi, R. E. Marotti et al., "Electrodeposition of $\mathrm{ZnO}$ thin films on $\mathrm{n}-\mathrm{Si}(100)$," Solar Energy Materials and Solar Cells, vol. 70, no. 3, pp. 245-254, 2001.

[12] D. Perednis and L. J. Gauckler, "Thin film deposition using spray pyrolysis," Journal of Electroceramics, vol. 14, no. 2, pp. 103-111, 2005.

[13] G. Korotcenkov, V. Brinzari, J. Schwank, and A. Cerneavschi, "Possibilities of aerosol technology for deposition of $\mathrm{SnO}_{2}$ based films with improved gas sensing characteristics," Materials Science and Engineering C, vol. 19, no. 1-2, pp. 73-77, 2002.

[14] M. Krunks and E. Mellikov, "Zinc oxide thin films by the spray pyrolysis method," Thin Solid Films, vol. 270, no. 1-2, pp. 33-36, 1995.

[15] O. Vigil, F. Cruz, A. Morales-Acevedo, G. Contreras-Puente, L. Vaillant, and G. Santana, "Structural and optical properties of annealed CdO thin films prepared by spray pyrolysis," Materials Chemistry and Physics, vol. 68, no. 1-3, pp. 249-252, 2001.

[16] C. Natarajan, N. Fukunaga, and G. Nogami, "Titanium dioxide thin film deposited by spray pyrolysis of aqueous solution," Thin Solid Films, vol. 322, no. 1-2, pp. 6-8, 1998.

[17] V. Brinzari, G. Korotcenkov, and V. Golovanov, "Factors influencing the gas sensing characteristics of tin dioxide films deposited by spray pyrolysis: understanding and possibilities of control," Thin Solid Films, vol. 391, no. 2, pp. 167-175, 2001.

[18] P. S. Patil and L. D. Kadam, "Preparation and characterization of spray pyrolyzed nickel oxide (NiO) thin films," Applied Surface Science, vol. 199, no. 1-4, pp. 211-221, 2002.

[19] T. P. Gujar, V. R. Shinde, and C. D. Lokhande, "Spray pyrolysed bismuth oxide thin films and their characterization," Materials Research Bulletin, vol. 41, no. 8, pp. 1558-1564, 2006.

[20] C. Chen, E. M. Kelder, P. J. J. M. van der Put, and J. Schoonman, "Morphology control of thin $\mathrm{LiCoO}_{2}$ films fabricated using the electrostatic spray deposition (ESD) technique," Journal of Materials Chemistry, vol. 6, no. 5, pp. 765-771, 1996.

[21] S. Golshahi, S. M. Rozati, R. Martins, and E. Fortunato, "P-type $\mathrm{ZnO}$ thin film deposited by spray pyrolysis technique: the effect of solution concentration," Thin Solid Films, vol. 518, no. 4, pp. 1149-1152, 2009.

[22] S. Salam, M. Islam, M. Alam et al., "The effect of processing conditions on the structural morphology and physical properties of $\mathrm{ZnO}$ and $\mathrm{CdS}$ thin films produced via sol-gel synthesis and chemical bath deposition techniques," Advances in Natural Sciences: Nanoscience and Nanotechnology, vol. 2, no. 4, Article ID 045001, 2011.
[23] X. Zhu, E. Defä, M. Aïd et al., "Preferential growth and enhanced dielectric properties of $\mathrm{Ba}_{0.7} \mathrm{Sr}_{0.3} \mathrm{TiO}_{3}$ thin films with pre annealed Pt bottom electrode," Journal of Applied Physics D, vol. 46, Article ID 105301, 2013.

[24] J. Karamdel, C. F. Dee, and B. Y. Majlis, "Effects of annealing conditions on the surface morphology and crystallinity of sputtered ZnO nano films," Sains Malaysiana, vol. 40, no. 3, pp. 209-213, 2011.

[25] J. Yang, J. Bei, and S. Wang, "Enhanced cell affinity of poly (D,L-lactide) by combining plasma treatment with collagen anchorage," Biomaterials, vol. 23, no. 12, pp. 2607-2614, 2002.

[26] B. D. Ahn, S. H. Oh, C. H. Lee, G. H. Kim, H. J. Kim, and S. Y. Lee, "Influence of thermal annealing ambient on Ga-doped $\mathrm{ZnO}$ thin films," Journal of Crystal Growth, vol. 309, no. 2, pp. 128-133, 2007.

[27] L. Wang, Y. Pu, W. Fang et al., "Effect of high-temperature annealing on the structural and optical properties of $\mathrm{ZnO}$ films," Thin Solid Films, vol. 491, no. 1-2, pp. 323-327, 2005.

[28] H. S. Kang, J. S. Kang, J. W. Kim, and S. Y. Lee, "Annealing effect on the property of ultraviolet and green emissions of $\mathrm{ZnO}$ thin films," Journal of Applied Physics, vol. 95, no. 3, pp. 1246-1250, 2004.

[29] P. Sagar, P. K. Shishodia, R. M. Mehra, H. Okada, A. Wakahara, and A. Yoshida, "Photoluminescence and absorption in sol-gelderived $\mathrm{ZnO}$ films," Journal of Luminescence, vol. 126, no. 2, pp. 800-806, 2007.

[30] P. Nunes, E. Fortunato, and R. Martins, "Influence of the posttreatment on the properties of $\mathrm{ZnO}$ thin films," Thin Solid Films, vol. 383, no. 1-2, pp. 277-280, 2001.

[31] P. Nunes, B. Fernandes, E. Fortunato, P. Vilarinho, and R. Martins, "Performances presented by zinc oxide thin films deposited by spray pyrolysis," Thin Solid Films, vol. 337, no. 12, pp. 176-179, 1999.

[32] K. H. Yoon and J. Y. Cho, "Photoluminescence characteristics of zinc oxide thin films prepared by spray pyrolysis technique," Materials Research Bulletin, vol. 35, no. 1, pp. 39-46, 2000.

[33] R. Ayouchi, F. Martin, D. Leinen, and J. R. Ramos-Barrado, "Growth of pure $\mathrm{ZnO}$ thin films prepared by chemical spray pyrolysis on silicon," Journal of Crystal Growth, vol. 247, no. 3-4, pp. 497-504, 2003.

[34] P. Uthirakumar and C.-H. Hong, "Effect of annealing temperature and $\mathrm{pH}$ on morphology and optical property of highly dispersible $\mathrm{ZnO}$ nanoparticles," Materials Characterization, vol. 60, no. 11, pp. 1305-1310, 2009.

[35] C. Periasamy, R. Prakash, and P. Chakrabarti, "Effect of post annealing on structural and optical properties of $\mathrm{ZnO}$ thin films deposited by vacuum coating technique," Journal of Materials Science: Materials in Electronics, vol. 21, no. 3, pp. 309-315, 2010.

[36] Y. Tong, Y. Liu, L. Dong et al., "Growth of $\mathrm{ZnO}$ nanostructures with different morphologies by using hydrothermal technique," Journal of Physical Chemistry B, vol. 110, no. 41, pp. 20263-20267, 2006.

[37] Q. Humayun, M. Kashif, and U. Hashim, “Area-selective ZnO thin film deposition on variable microgap electrodes and their impact on UV sensing," Journal of Nanomaterials, vol. 2013, Article ID 301674, 5 pages, 2013.

[38] Z. B. Fang, Z. J. Yan, Y. S. Tan, X. Q. Liu, and Y. Y. Wang, "Influence of post-annealing treatment on the structure properties of ZnO films," Applied Surface Science, vol. 241, no. 3-4, pp. 303308, 2005. 
[39] M. Rusop, K. Uma, T. Soga, and T. Jimbo, "Post-growth annealing of zinc oxide thin films pulsed laser deposited under enhanced oxygen pressure on quartz and silicon substrates," Materials Science and Engineering B, vol. 127, no. 2-3, pp. 150153, 2006.

[40] N. H. Al-Hardan, M. J. Abdullah, A. Abdul Aziz, H. Ahmad, and L. Y. Low, "ZnO thin films for VOC sensing applications," Vacuum, vol. 85, no. 1, pp. 101-106, 2010.

[41] R. Hong, H. Qi, J. Huang, H. He, Z. Fan, and J. Shao, "Influence of oxygen partial pressure on the structure and photoluminescence of direct current reactive magnetron sputtering $\mathrm{ZnO}$ thin films," Thin Solid Films, vol. 473, no. 1, pp. 58-62, 2005.

[42] A. B. Djurišić, W. C. H. Choy, V. A. L. Roy et al., "Photoluminescence and electron paramagnetic resonance of $\mathrm{ZnO}$ tetrapod structures," Advanced Functional Materials, vol. 14, no. 9, pp. 856-864, 2004.

[43] W. Q. Peng, S. C. Qu, G. W. Cong, and Z. G. Wang, "Structure and visible luminescence of $\mathrm{ZnO}$ nanoparticles," Materials Science in Semiconductor Processing, vol. 9, no. 1-3, pp. 156-159, 2006.

[44] B. Panigrahy, M. Aslam, D. S. Misra, M. Ghosh, and D. Bahadur, "Defect-related emissions and magnetization properties of $\mathrm{ZnO}$ Nanorods," Advanced Functional Materials, vol. 20, no. 7, pp. 1161-1165, 2010.

[45] A. B. Djurišić, Y. H. Leung, K. H. Tam et al., "Defect emissions in $\mathrm{ZnO}$ nanostructures," Nanotechnology, vol. 18, no. 9, Article ID 095702, 2007.

[46] S. Cho, J. Ma, Y. Kim, Y. Sun, G. K. L. Wong, and J. B. Ketterson, "Photoluminescence and ultraviolet lasing of polycrystalline $\mathrm{ZnO}$ thin films prepared by the oxidation of the metallic $\mathrm{Zn}$," Applied Physics Letters, vol. 75, no. 18, pp. 2761-2763, 1999.

[47] S. Fujihara, Y. Ogawa, and A. Kasai, "Tunable visible photoluminescence from $\mathrm{ZnO}$ thin films through $\mathrm{Mg}$-doping and annealing," Chemistry of Materials, vol. 16, no. 15, pp. 29652968, 2004.

[48] S. Chen, Z. Zhao, B. Z. Tang, and H. S. Kwok, "Growth methods, enhanced photoluminescence, high hydrophobicity and light scattering of 4, 4' -bis(1, 2, 2-triphenylvinyl)biphenyl nanowires," Organic Electronics, vol. 13, pp. 1996-2002, 2012.

[49] V. S. Reddy, K. Das, A. Dhar, and S. K. Ray, "The effect of substrate temperature on the properties of ITO thin films for OLED applications," Semiconductor Science and Technology, vol. 21, no. 12, pp. 1747-1752, 2006.

[50] A. L. Mercado, C. E. Allmond, J. G. Hoekstra, and J. M. FitzGerald, "Pulsed laser deposition vs. matrix assisted pulsed laser evaporation for growth of biodegradable polymer thin films," Applied Physics A, vol. 81, no. 3, pp. 591-599, 2005.

[51] R. Jones and D. Fried, "Attenuation of 1310-nm and 1550-nm laser light through sound dental enamel," in Lasers in Dentistry VIII, vol. 4610 of Proceedings of SPIE, pp. 187-190, San Jose, Calif, USA, January 2002.

[52] A. H. Jayatissa, S.-T. Cheng, and T. Gupta, "Annealing effect on the formation of nanocrystals in thermally evaporated tungsten oxide thin films," Materials Science and Engineering B, vol. 109, no. 1-3, pp. 269-275, 2004. 

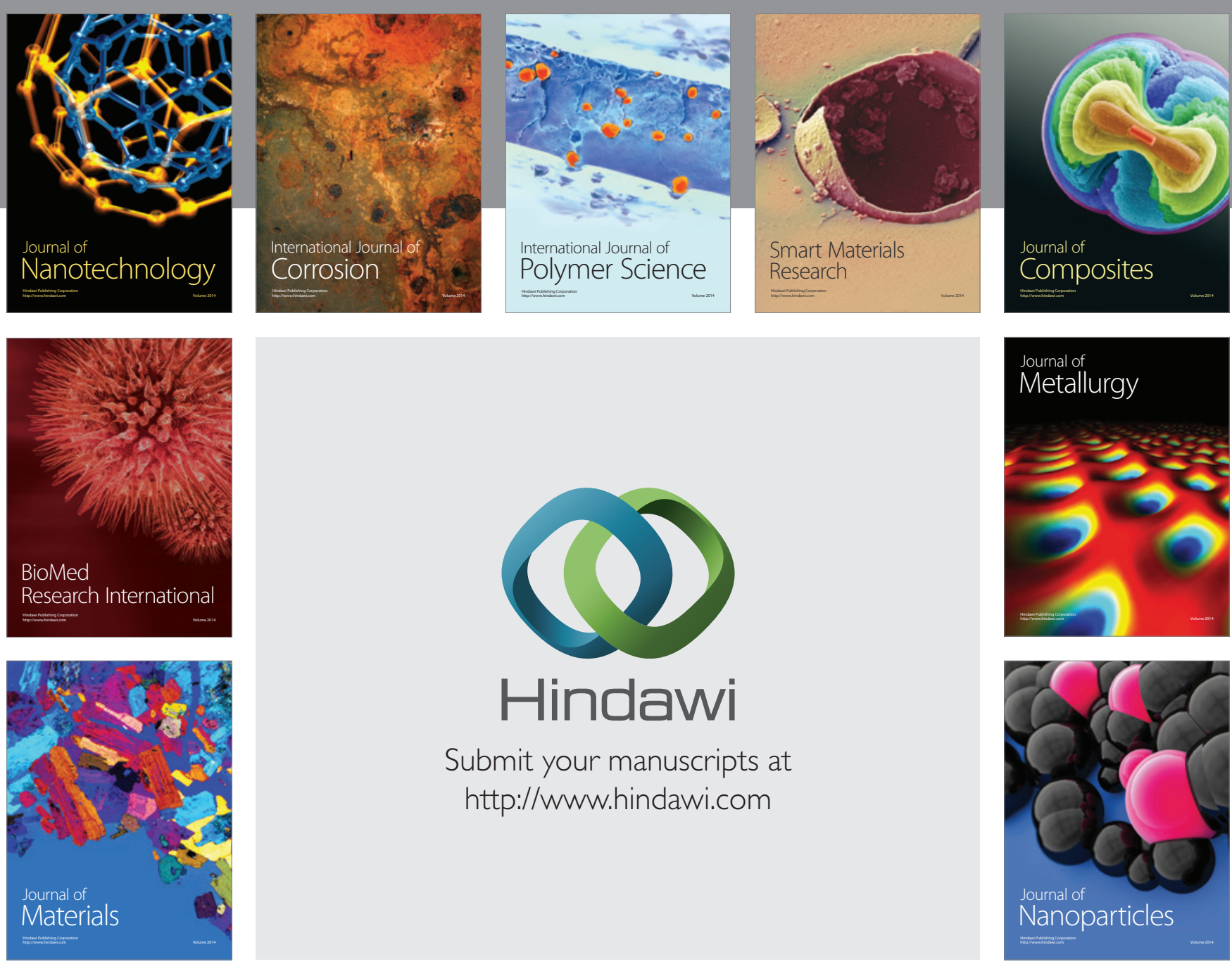

Submit your manuscripts at http://www.hindawi.com
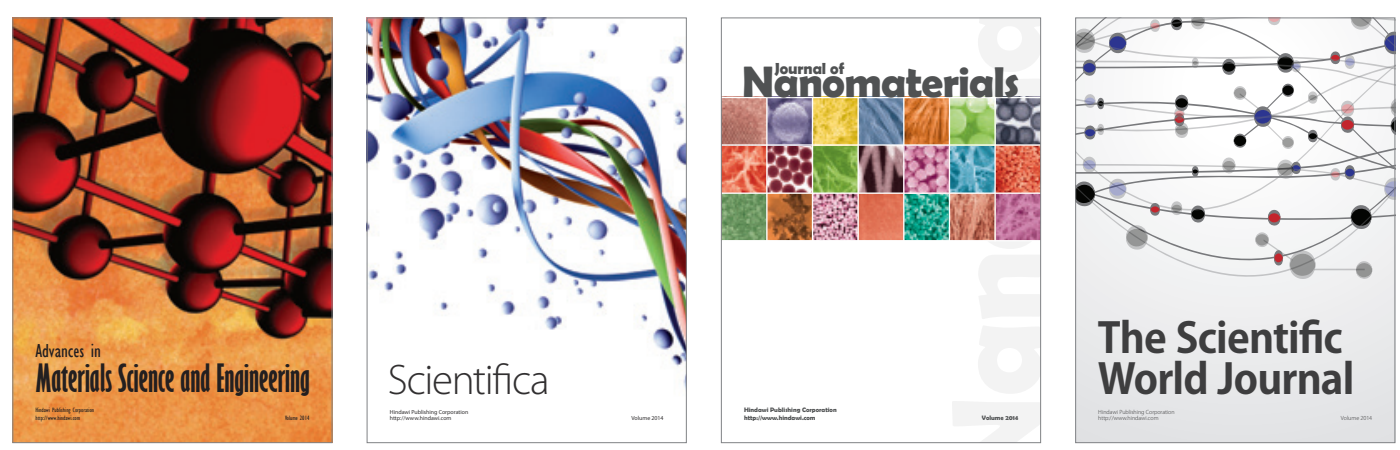

\section{The Scientific World Journal}
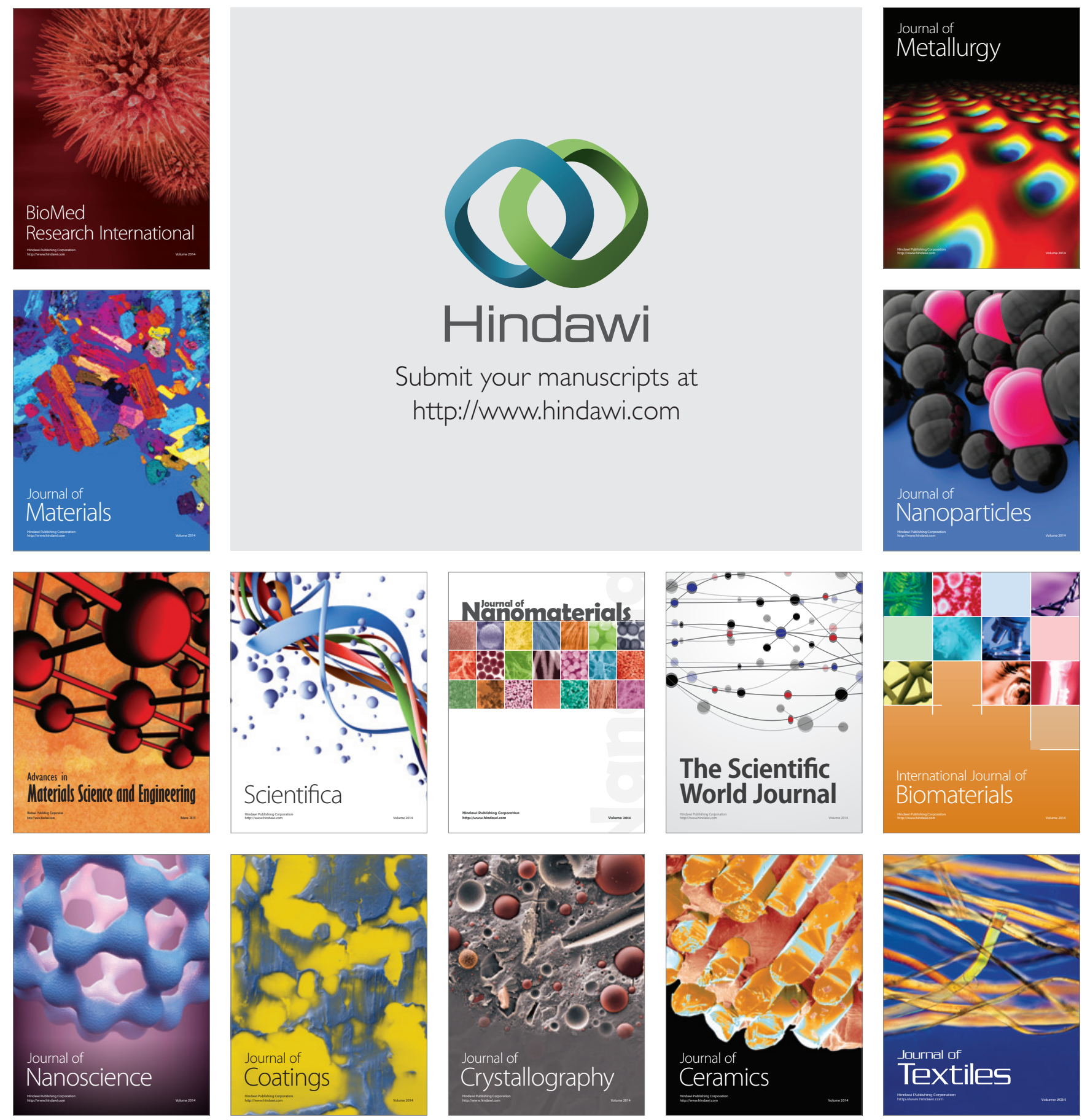